\title{
COMUNIDAD, SOCIEDAD. REFLEXIONES DESDE LA HISTORIA CONCEPTUAL
}

\author{
Ignacio Mazzola \\ Universidad de Buenos Aires - CONICET,Argentina
}

\begin{abstract}
Resumen.- En este trabajo nos interrogamos por la historia de los conceptos modernos "comunidad" y "sociedad", que se relacionan como contrarios asimétricos con referentes distintos que sin embargo tienen un origen común en el concepto aristotélico koininía cuyo referente es la polis griega. A partir de esta circunstancia nos preguntamos si la experiencia de la que los conceptos diferenciados son indicadores y factores es pura y exclusivamente moderna o bien si en el pasado pudo darse una experiencia "similar". Si ese fuera el caso, deberíamos ser capaces de encontrar el modo en el que esa experiencia se articuló conceptualmente. Ello nos lleva a analizar el pensamiento socio-político de Cicerón y San Agustín, localizados ambos en el cruce de tradiciones intelectuales diversas y fuertemente marcados por coyunturas históricas específicas. Concluimos con algunas reflexiones en torno a las enseñanzas que cabe extraer de la historia conceptual para la teoría social.
\end{abstract}

Palabras clave.- Koinonía, comunidad, sociedad, conceptos, experiencias.

Abstract.- In this paper we take as our subject the history of the modern concepts "community" and "society", which relate to each other as asymmetric counterconcepts with different references although they have a common origin in the Aristotelian koinonía, the reference of which was the Greek polis. Departing from that consideration we ask whether the experience of which the differentiated concepts are indicatives and factors is purely and exclusively modern or if it is possible to find a "similar" experience in the past. In that case, we should be able to find the way in which that experience was then conceptualized. That takes us to analyze the social and political thought of Cicero and Saint Augustine, located both at the crossroad of different intellectual traditions and marked by specific historical circumstances. We conclude with a few reflections on the gains that social theory can expect from the history of concepts.

Keywords.- Koinonía, community, society, concepts, experiences.

No se puede decir que algo es, sin decir lo que es. Al pensarlos, se refieren los facta a conceptos y no es indiferente a cuáles.

Friedrich Schlegel

\section{Introducción}

Desde el sentido común imperante en la actualidad resulta sorprendente advertir que la distinción conceptual entre comunidad y sociedad es propia de la modernidad, es decir, que es una distinción relativamente reciente. Esta sorpresa deriva del hecho de que para nosotros se trata de conceptos que tienen, al menos en la mayoría de sus usos, un significado perceptiblemente diferente. Cierto es que nos sería difícil decir con exactitud cuál es la diferencia 
en sus significados, ${ }^{1}$ pero pocas veces nos pasa inadvertida la intencional (por no decir estratégica) elección de una u otra expresión por determinados hablantes en determinados contextos; y menos aún dejamos de percibir las particulares connotaciones de cada una de ellas. Se trata por lo tanto de una distinción que para nosotros tendría un hondo -aunque oscuro- arraigo en "las cosas mismas": la comunidad no es lo mismo que la sociedad, y mucho menos es nuestra comunidad idéntica con la sociedad en la que vivimos, o eso es lo que parece.

Peor aún es la situación para los lectores de bibliografía sociológica. A la intuitiva pero poco clara diferencia entre los significados de estos dos conceptos se suma el hecho de que ambas expresiones se encuentran entre las categorías clásicas de la tradición sociológica; categorías pretendidamente formales o típico-ideales, que quieren tener un significado unívoco, pero que se ven constantemente sobrepasadas -incluso allí donde son usadas por autores que pretenden sujetarlas y sujetarse a una definición- por las múltiples significaciones y connotaciones de sus usos conceptuales socio-político cotidianos.

Se trata, por otro lado, no sólo de conceptos fundamentales del lenguaje sociopolítico (estructuradores del modo en que nos representamos el orden social vigente) y de categorías de la tradición científica sociológica con significados, en ambos contextos, diferentes. Sucede además que estos conceptos se presentan muchas veces como expresiones polarmente opuestas, antitéticas. Más aún: cuando son utilizadas como expresiones contrarias, frecuentemente se las coloca también, implícita o explícitamente, en una relación asimétrica: una de ellas es valorada en detrimento de la otra, reivindicada por oposición, o simplemente definida por la negativa. ${ }^{2}$

Entonces, resulta que tenemos dos expresiones, comunidad y sociedad, que tienen diferentes significados, tanto en nuestra conceptualidad político-social cotidiana como en la tradición científica sociológica; significados que además son muchas veces contrarios y también, a veces, asimétricos. Y sin embargo se puede argumentar, de allí la sorpresa mencionada al inicio, que estas palabras no eran asimétricamente contrarias ni tenían significados diferentes. Más aún, según parece, ni siquiera eran dos palabras/conceptos, sino una/o. Entonces, si la diferencia, la oposición y la asimetría entre ellas son propias de la modernidad, cabe preguntarse: ¿Cómo hemos llegado a esta situación? ¿Qué ha pasado a nivel socio-histórico y conceptual-teórico para que se abra una brecha, antes inexistente, entre comunidad y sociedad? ¿Qué experiencias típicamente modernas han captado (captan) y moldeado (moldean) esas expresiones, y qué problemas nos han deparado (nos deparan) esas experiencias $y$ expresiones? Sin duda, la respuesta cabal a estas preguntas exigiría una investigación histórico-comparativa de las transformaciones socio-

\footnotetext{
1 Difícil nos sería también decir cuál es exactamente el significado de la mayoría de las palabras que usamos día a día.

2 Para la idea de "conceptos contrarios asimétricos" ver: Koselleck, R. "Sobre la semántica histórico-política de los conceptos contrarios asimétricos”, en: Ibíd., 1993: 205-250.
} 
estructurales y cosmovisivas que se producen entre el mundo Antiguo-Medieval y el mundo Moderno. Una investigación que no podemos acometer aquí. Sin embargo, la sorpresa puede también ser elaborada a través de preguntas más modestas. Cabe preguntarse, en efecto, si es cierto que la experiencia de la que los conceptos diferenciados son indicadores y factores es pura y exclusivamente moderna o bien si en el pasado pudo darse una experiencia "similar". Si este último fuera el caso, deberíamos admitir que esa experiencia debió encontrar algún tipo de expresión conceptual, ${ }^{3}$ aunque no haya sido mediante la distinción que nosotros conocemos y aplicamos. La pregunta sería entonces por modos de conceptualización que en relación a una experiencia similar sean (hayan sido) "equivalentes funcionales" del par conceptual operativo para los modernos. La experiencia de referencia sería la de una clara limitación, restricción / ampliación o necesidad de especificación del grupo de pertenencia, ya sea en relación con otros grupos o colectivos o respecto de un concepto genérico indeterminado. A su vez, y teniendo en cuenta el carácter "contrario asimétrico" del par conceptual comunidad / sociedad, puede ser interesante preguntarse por las premisas que impiden o hacen posible la aparición de una distinción y el modo en que determinan el carácter complementario, contrario, simétrico o asimétrico de los conceptos en juego. Así, los posibles "equivalentes funcionales" harían más claramente visibles las alternativas (y los problemas que ellas deparan) fundantes de la modernidad.

Tal vez sea cierto que "la filosofía empieza con la sorpresa", como este texto, pero en todo caso no lo hace para dejarnos en ella. La filosofía es el intento por dejar atrás la sorpresa a través de la comprensión. Se podría entender la filosofía como análisis conceptual, ${ }^{4}$ y el análisis conceptual como historia de los conceptos (y sus premisas). Mediante la historia conceptual se nos hacen visibles otras experiencias históricas. A partir de una experiencia históricosocial ajena, articulada conceptualmente de un modo diferente pero que se inscribe en una misma tradición histórica, podremos preguntarnos por las transformaciones que nos separan de aquella, cambios en la historia social y en la historia conceptual (y en las premisas de los sistemas conceptuales) que están a la base de nuestra experiencia y conceptualización histórica. La identificación y seguimiento de estos cambios y transformaciones nos permitirá comprender mejor la sociedad en la que vivimos y la "teoría social" que domina nuestras representaciones (de sentido común o no) sobre ella. En cualquier caso, la historia de los conceptos que estoy en condiciones de llevar adelante es muy limitada y en consecuencia las hipótesis y reflexiones que aquí se presentan no quieren ser más que un ejercicio de investigación.

\footnotetext{
${ }^{3}$ De hecho, si una experiencia tal nos fuera hoy accesible sólo lo sería a condición de haber sido conceptualizada, y precisamente a través de los conceptos en los cuales quedó articulada.

${ }^{4}$ Siguiendo la sugerencia de Hans-Georg Gadamer. Su artículo de 1970 "La historia del concepto como filosofía" en: Gadamer, 2005b: 81-93
} 


\section{Koinonía, Communitas, Societas}

Dije más arriba que las expresiones comunidad y sociedad premodernas no sólo tenían idénticos significados sino que además provienen de una única palabra. Esta es una afirmación es un tanto imprecisa, y conviene ser más claro.

La palabras castellanas comunidad y sociedad son traducciones de las palabras latinas communitas y societas, al igual que, en la actualidad, las palabras alemanas Gemeinschaft y Gesellschaft. En latín, por lo tanto, tenemos dos palabras, y no una. Sin embargo, desde el punto de vista de la eficacia histórica (Gadamer) en la tradición filosófico-política occidental las expresiones latinas communitas y societas aparecen por primera vez en la obra de Cicerón como traducciones alternativas e indistintas de una única palabra: la palabra griega-aristotélica koinonía (Riedel, 1976: 127). Y así, el investigador interesado por la comunidad y la sociedad debe tomar una decisión respecto de su punto de partida.

Puede, en primer lugar, permanecer en el ámbito de la lengua latina, partiendo de la etimología de las propias palabras communitas y societas, rastreando sus raíces y los sufijos que las acompañan, y las variaciones de unas y otros en la historia de la red semántica que las incluye, siempre en el mismo ámbito lingüístico (este es, por ejemplo, el camino elegido por Roberto Espósito en su libro Communitas -donde, por otro lado, se ignora abiertamente la sinonimia total -F. Schalk citado en Riedel, 1977: 127- entre communitas y societas en las lenguas latino-románicas, sinonimia que lógicamente relativiza la importancia concedida a la raíz y sufijos de una sola de esas palabras en la determinación de su significado "propio"). $O$ bien puede preguntarse por el tipo de interés que tiene en la investigación y evaluar si el propio punto de vista no lo obliga a perseguir más allá de las etimologías documentadas las filiaciones relevantes para el tipo de investigación propuesta. Este es el camino aquí elegido, y para el caso quiere decir lo siguiente: nos interesamos en las expresiones comunidad y sociedad no como meras palabras sino como conceptos políticos-sociales fundamentales, ${ }^{5}$ y nos dejamos guiar por la Wirkungsgeschichte ${ }^{6}$ de estos conceptos, viéndonos remitidos así, vía Cicerón, a la koinonía aristotélica antes que al numus de Espósito. ${ }^{7}$

\footnotetext{
${ }^{5}$ Koselleck, 2009: 92-105; 1996: 59-70; 1993: 105-126.

${ }^{6}$ Gadamer, 2005: 370-377 y Grondin, 2003:146-153.

${ }^{7}$ Un distinto punto de partida no es la única diferencia que tengo con Espósito. Sin embargo, la discusión detallada de las tesis de Espósito requeriría otro trabajo monográfico. Aquí quisiera simplemente agregar que encuentro en las ideas de (a) la existencia de "conceptos políticosociales fundamentales" y de (b) la eficacia histórica de los mismos, argumentos para defender mi decisión de remitirme a Aristóteles y su recepción latina (de Cicerón a Bruni) a la hora de revisar la historia conceptual de comunidad y sociedad, precisamente en su carácter de conceptos político-sociales fundamentales. Por el contrario, me parece que, de acuerdo con la intención de Espósito, su punto de partida, la reconstrucción etimológica de communitas, carece de justificación y no sirve más que para llenar hojas en blanco; pura retórica, en el mal
} 
Ahora bien, el hecho de que Cicerón, y la tradición latina-románica, incluyendo el pensamiento cristiano de San Agustín, pudiera durante siglos usar intercambiablemente las palabras communitas y societas para traducir una única palabra de origen griego, es decir, el hecho de que no tuviera necesidad de romper esa sinonimia, parecería hablar, desde el punto de vista moderno de la distinción conceptual consumada, de una cierta continuidad en la manera de conceptualizar la experiencia, en las premisas de esa conceptualización y en la experiencia misma. Sin embargo, ¿acaso no se producen entre el Aristóteles de la polis, el Cicerón de la república y el San agustín de la debacle del imperio transformaciones históricas (sociales, políticas, intelectuales) profundas, que modifican las relaciones de los individuos con los demás individuos, cercanos y lejanos? ¿Cuál fue el modo en que se conceptualizó en cada caso la experiencia de la pertenencia social / comunitaria del individuo? ¿Cuáles eran las premisas de estas conceptualizaciones, y qué experiencias quedaban así apresadas? La respuesta a estas preguntas es el punto de partida para futuras investigaciones en las que se busque, a través del cambio semántico, las rupturas que tanto a nivel de las experiencias históricas como a nivel de las premisas y de las modalidades de la conceptualización nos permitan aclarar la distinción, oposición y asimetría entre comunidad y sociedad propias de la modernidad. ${ }^{8}$

sentido. Me explico: el filósofo italiano afirma que en el presente "nada parece más a la orden del día, nada más requerido [y] reclamado" que "pensar la comunidad", "y sin embargo, nada menos a la vista. Nada tan remoto, desplazado, postergado, para un tiempo por venir, para un horizonte lejano e indescifrable" (Espósito, 2003: 21). Por lo demás, las filosofías que actualmente quieren ocuparse del asunto y que conectan con el pensamiento político-social occidental están condenadas al fracaso: "ellas no sólo se inscriben en esta impensabilidad [de la comunidad], sino que constituyen incluso su expresión más sintomática". (Ibíd.) La forma misma de pensar de esas filosofías y de la tradición en la que se inscriben las lleva a distorsionar y pervertir cualquier concepto de comunidad. Espósito se aboca entonces, a fin de proveer el tan necesario y requerido concepto, a buscar "un punto de partida (...) externo e independiente (...) en el origen de la cosa misma. Esto es, en la etimología del término latino communitas". (Ibíd., 25) Ahora bien, ¿qué autoridad puede reclamar el significado "original" de la palabra (dejando de lado la posibilidad de cuestionar la idea misma de que habría un tal significado primario, fundante, originario, que se correspondería con la "esencia" de la comunidad)? $\mathrm{Si}$, dicho brevemente, el significado es el uso, si la semántica está subordinada a la pragmática, ¿cómo concebir que se puede acusar a todo el pensamiento político occidental de ser incapaz de pensar correctamente la comunidad porque yerra un pretendido significado "original"? En definitiva, no hay significados originarios, sino usos, y relaciones inferenciales entre ellos (Brandom, 1994). Por lo tanto, si Espósito quiere afirmar que la communitas es "el conjunto de personas a las que une, no una propiedad, sino (...) un deber o una falta" (Ibíd., 29), puede hacerlo. Pero no porque ese sea el significado "originario" (y en consecuencia "legítimo", o "correcto", y fatalmente incomprendido, viciado por las premisas del pensamiento logo-céntrico, identitario, etc., etc.) del término, sino simplemente porque así quiere entender y usar la expresión. Y si ello le sirve para responder a la pregunta "¿cómo derribar las murallas del individuo salvando el don singular que encierra?" (Ibíd., 49 - mis cursivas. Pregunta: ¿también aquí se quiere seguir pensando, de alguna forma, al individuo?) bienvenido sea. Pero habrá que decir que él no es el único en querer "descentrar" (Ibíd., 31) al individuo sin eliminarlo (cosa que revela sólo al final, y que lo pone en un bote repleto de gente), que la etimología de meras palabras no parece el medio más apropiado para hacerlo, y que el punto de partida "externo e independiente" es una pretensión absurda.

${ }^{8}$ Para entender del modo más fiel posible la forma de la conceptualización y la experiencia histórica del mundo griego se debe evitar proyectar sobre ella los esquemas y conceptos que caracterizan al pensamiento moderno. En el presente caso, se deben evitar sobre todo los 


\section{La koinonía en el mundo antiguo: de la philía a la polis ${ }^{9}$}

El concepto de koinonía es elaborado por Aristóteles fundamentalmente en dos contextos: el Libro VIII de Ética Nicomaquea y el Libro I de Política. Podemos apoyarnos en ellos para extraer las premisas y los caracteres que en el pensamiento griego-aristotélico son constitutivos de una relación entre dos o más seres humanos.

En el primer texto, el Libro VIII de Ética Nicomaquea, Aristóteles se ocupa de la amistad, "una cosa sumamente necesaria para la vida" (EN, 1155a 3). Si en ese contexto tiene sentido hablar de la koinonía (comunidad/sociedad) entre los hombres ello se debe no sólo al particular significado de este último concepto sino también a que el concepto griego de philía excede en mucho el concepto de amistad moderno, en su amplitud semántica y en sus implicaciones.

Philía es para Aristóteles el nombre de aquello que liga a los seres humanos. El vínculo siempre ya dado entre las personas se denomina amistad, en general (dejando a un lado los distintos tipos de amistad). Así, es la amistad la que vincula tanto a los esposos como a los padres e hijos; a los mercaderes y comerciantes tanto como a los conciudadanos; es, incluso, lo que vincula a la humanidad toda (es decir, a los helenos). En este sentido afirma Aristóteles: "para un ser humano todo ser humano es algo familiar y amigo" (EN VIII 1 1155a 22-23). Luego, la amistad es algo absolutamente necesario, pues ningún ser humano puede vivir sin amigos sin dejar de ser humano. La amistad se da, entonces, por naturaleza. Está en la naturaleza humana el tener y el habertenido-siempre-ya amigos. Sin embargo, no hay amistad sin una conciente reciprocidad en la afección y en el querer un bien para el otro, pues "¿cómo podría uno llamar [a dos o más seres humanos] 'amigos' si la manera en que están dispuestos [uno hacia otro] les pasa inadvertida?" (1156a 3-5). La amistad queda así asociada con el reconocimiento recíproco. Por ello, no hay amistad ni con las cosas inanimadas ni con los esclavos, cuando ellos no son seres humanos (pero sí la hay cuando lo son - 1161b 5-7).

\footnotetext{
"giros sociológicos". Esto no sólo para acercarnos al sentido de los textos griegos sino también, y fundamentalmente, para comprender mejor el sentido de nuestros conceptos y la estructura de nuestros esquemas conceptuales. El primer lugar en que esa proyección "tergiversante" se realiza es la traducción. Luego, la lectura retrospectiva que se realiza a partir de un problema (o interés) actual ignorando precisamente los riesgos interpretativos de que nos advierte la Historia Conceptual, como disciplina. (Por lo demás, esta última sabe perfectamente que siempre es un interés o problema actual, propio del investigador y su contexto, el que conduce a la lectura e interpretación de textos antiguos.)

${ }^{9}$ Para lo que sigue, Aristóteles 2007, Libro VIII, y Aristóteles, 2005, Libro I, cap. 1 y 2 . En la presentación del pensamiento de Aristóteles me aparto de Riedel, pero para llegar a las mismas conclusiones respecto del concepto de koininía: Riedel, 1977: 123-147; y: Riedel, 1976: 115-136.
} 
Ahora bien, esta relación básica entre los seres humanos como tales, sin la cual ellos no serían más que bestias (o, en el mejor de los casos, Dioses), presenta distintos tipos o asume diversas formas de acuerdo con la razón o motivo por el cual existe o se la establece. Esa razón o motivo es su fundamento, el fundamento del tipo de amistad de que se trate; es lo que la sostiene, y ella cesa de existir cuando aquel deja de "operar". Esos motivos o razones son la utilidad, el placer y el bien, las tres "clases de lo amable" (EN VIII 2 y 3). Así, o hay amistad debido al provecho que las partes obtienen de ella, o bien debido al placer que les procura la mutua compañía, o bien hay amistad por "la calidad de bueno" del amigo, esto es, debido a lo que el amigo es en sí y por sí, y no por lo que para uno resulta de su relación con el otro. Estos distintos tipos de amistad se diferencian a su vez a lo largo de otros dos ejes: (a) la homogeneidad/heterogeneidad de los intereses de los amigos y (b) la igualdad o desigualdad entre ellos.

De aquí surge una compleja "teoría de la amistad" que no es necesario desarrollar en su totalidad. Baste decir que la verdadera y completa amistad, la que alcanza el fin propio de la relación propiamente humana, es aquella en la cual los amigos son tales por el bien, son iguales entre sí y hay homogeneidad en la orientación hacia el bien. Esta forma de la amistad se identifica con la justicia, con lo justo en el trato entre los seres humanos. Esta forma de relacionarse provee el modelo, paradigmático, de las relaciones justas. Y de allí se sigue que a cada forma "descendente" de amistad corresponda un tipo de justicia específico, y por lo tanto un tipo de derecho, que "media" entre las partes. La amistad, en todas sus formas, supone la justicia y el derecho entre los amigos, formas de justicia y derecho que varían con los tipos de amistad. Es el correspondiente tipo de justicia en el trato el que provee la estabilidad de la relación, el que fija las expectativas recíprocas que es dable tener. Allí donde cesa completamente la amistad (en la relación del ser humano con lo inhumano) cesa la justicia y el derecho. Inversamente, donde se realiza completamente la amistad, en el trato de los buenos e iguales orientados al bien, se realiza completamente la justicia y el derecho. ${ }^{10}$

Ahora bien, todavía en el contexto del Libro VIII de la Ética Nicomaquea, dedicado a la philía, en el capítulo IX, Aristóteles de pronto introduce el concepto de koinonía:

"A lo que parece, la amistad y lo justo (...) se refieren a las mismas cosas y se dan entre los mismos [hombres], pues (...) en toda koinonía hay una forma de lo justo, y también amistad" (EN VIII 9 1159b 24-27).

Más aún, sólo hay amistad entre seres humanos "en la medida en que están reunidos en koinonía" (1159b 29) puesto que "la amistad radica en la koinonía" (1159b 29-32 -mis cursivas). De ello se sigue que "las clases de amistad se corresponden con las clases de koinonía" (1160a 30). Se puede decir entonces que si, como el mismo Aristóteles afirma, "toda amistad se basa, pues, en una

\footnotetext{
10 "Todo ser humano tiene cierta relación de justicia con todo el que es capaz de compartir una ley y una convención, $y$, por tanto, una amistad, en la medida en que es un ser humano". (EN VIII 11 1161b 6-9)
} 
koinonía" (1161b 14), toda koinonía, a su vez, se basa en un tipo de amistad. Amigos son así los compañeros, los miembros de una reunión en torno a algo común, y los tipos de philía / koinonía se distinguen a lo largo de los tres criterios antes mencionados y según el carácter de ese algo común: hay koinonía entre esposos, entre padres e hijos; koinonía de navegación, de milicia, religiosas; también los compañeros de la tribu o el demos son amigos y por lo tanto la tribu y el demos son tipos de koinonía.

De los pasajes citados, todos correspondientes al capítulo 9 del Libro VIII de la Ética nicomaquea, parece desprenderse que el concepto de amistad es coextensivo con el de koinonía; más aún, que koinonía y philía son, en cierto sentido, sinónimos. ${ }^{11} \mathrm{~A}$ falta de una aclaración explícita por parte de Aristóteles, me atrevería a afirmar que la diferencia entre ellas sería la siguiente: si la amistad es lo que une, la koinonía es lo que resulta de la (mutua) disposición a la unión; si la amistad es la disposición a un actuar en común en pos de un fin común, la koinonía es el actuar en común mismo. Luego, una no puede estar presente sin la otra, y por ello a cada tipo del género amistad corresponde un tipo específico dentro del conjunto de las koinoniai, y viceversa. De ahí la coextensividad de los conceptos.

De este modo, el concepto de koinonía en el contexto de discusión de las diferentes formas de amistad (y sus correspondientes formas de justicia, tipos de amistad y justicia que existen o se establecen según diversos fines, la igualdad / desigualdad de los amigos y la homogeneidad / heterogeneidad de los fines de las partes) hace referencia a todas las formas de asociaciones humanas, tanto a aquellas basadas en algún tipo de contrato como a las

\footnotetext{
${ }^{11}$ Al inicio del capítulo IX del Libro VIII de la Ética nicomaquea, anticipando los parágrafos en donde se encuentran los fragmentos citados, el traductor de la edición que manejamos, Eduardo Sinnott, introduce una nota a pie de página en la que afirma: "Aristóteles pasa [aquí] de la amistad en el dominio privado o individual a la amistad en el marco de las distintas formas de asociación entre los hombres". (Aristóteles, 2007: 303, nota 1633) Pues bien, no estoy seguro de que esta afirmación, que pretende ser una aclaración respecto del "sorpresivo" salto que se produce en el texto aristotélico, tenga sentido. No me parece convincente la idea de que con la introducción de la koinonía en el contexto de la discusión respecto de la philía lo que Aristóteles esté haciendo es pasar del plano individual/privado al plano colectivo/público. En primer lugar, no estoy seguro de que la distinción moderna (Habermas, 2004) entre lo público y lo privado tenga aquí sentido. En segundo lugar, a lo largo del Libro VIII Aristóteles no deja nunca de analizar la amistad como relación entre dos o más personas, esto es, nunca habla de la amistad desde el punto de vista del individuo aislado, con lo cual presupone que se trata de una forma de asociación entre hombres, y la pluralidad supone, de algún modo, la publicidad de la relación. Por otro lado, es recién en el Libro IX que Aristóteles dice que concibe a la amistad como la extensión hacia otros de las disposiciones que el ser humano tiene para consigo mismo. Pero aún suponiendo que en el Libro VIII Aristóteles anticipara y dejara abierto un tema del Libro IX, me parece que no tendría sentido hablar de "amistad" si no se supusiera la relación entre los seres humanos, es decir, si no se concibieran las disposiciones de uno para consigo mismo como las de un ser que se-encuentra-consigo-mismo siempre-ya en el contexto de sus relaciones con otros. En consecuencia, me inclino a pensar que la introducción del concepto de koinonía en la discusión respecto de la philía responde a razones sistemáticas y no a un salto entre los "dominios" de lo privado y lo público. Esas razones sistemáticas, conceptuales, son las que intento reconstruir, proponiendo una interpretación del texto. Señalo de paso que Riedel, al intentar extraer los caracteres del concepto de koinonía del contexto de discusión de la philía afirma que esos conceptos no son idénticos, pero deja sin explicar la diferencia (Riedel, 1977: 129).
} 
formas más básicas y naturales de la convivencia humana. ${ }^{12}$ Los seres humanos se agrupan $y$ se hallan agrupados siempre en koinoniai (comunidades / sociedades), forman koinoniai que tienen fines propios y normas que gobiernan la vida en común propia de la koinoniai de que se trate. Estos son criterio relevantes para la diferenciación de los tipos de agrupamientos, pero no establecen saltos cualitativos entre ellos desde el momento en que las koinoniai son necesarias por naturaleza para la vida humana.

Ahora bien, Aristóteles señala, sin embargo, que por amplio que sea el espectro de las koinoniai posibles, constituidas sobre la base de algún tipo de amistad entre los seres humanos, ellas "se muestran todas como partes de la koinonía politiké" (1160a 9-10), a la cual están subordinadas (1160a 20). Así, la verdadera y completa koinonía es la de tipo político, la koinonía politiké, sinónimo de polis. Esto lleva a Manfred Riedel a afirmar que en el contexto de la Ética Nicomaquea "todas estas koinoniai abarcadas por el derecho y la amistad no constituyen ni un ámbito independiente entre los individuos y la polis, ni tienen un concepto propio, independiente del que aquella (...) de la cual son un analogon conceptual' (Riedel, 1977: 129 -mis cursivas). Es entonces la koinonía politiké la que debe interesarnos, en tanto ella constituye el tipo propiamente humano de koinonía.

El concepto de la misma, así como los principios de su conceptualización, se hacen completamente explícitos sólo en el Libro I de Política. Allí, la verdadera koinonía, la sociedad o comunidad en sentido estricto, es la koinonía politiké, o polis. En la primera frase de Política se dice que la ciudad, la polis, es un tipo de koinonía, pero no un tipo entre otros, sino el tipo de koinonía que está por encima de todos los otros tipos y que los incluye. Esta preeminencia la explica el hecho de que si bien todas las comunidades / sociedades se constituyen con vista a algún bien, sólo la koinonía politiké tiende al bien supremo, y por ello se llama ciudad (polis). ${ }^{13}$ Es este tipo de agrupamiento, de asociación, el que constituye el fundamento de los otros tipos de koinonía, que no son sino formas derivadas, secundarias, de aquella. No se piensa a la polis a partir de -sobre la base de, por analogía con- la comunidad familiar o la sociedad contractual, sino al revés: a éstas sobre la base de aquella, ya que sólo la koinonía de tipo político representa el tipo propiamente humano de asociación o agrupamiento. Las koinoniai diferentes de la koinonía politiké son, como dice Riedel, conceptualmente análogas a ésta, pero no tienen una existencia separada, no constituyen entes en sí mismas, sino que es la polis la que "les presta su ser", por decirlo de algún modo. Precisamente, la koinonía politiké es la verdadera y completa koinonía porque es la primera forma de comunidad / sociedad

\footnotetext{
12 Reténganse estas características conceptuales mínimas del concepto de koinonía ya que ellas contradicen punto por punto los ejes de la conceptualización contrapuesta Gemeinschaft I Gesellschaft tanto en la versión de F. Tönnies (1947) como en la de M. Weber (2004)

13 "Puesto que vemos que toda ciudad es un tipo de comunidad y toda comunidad está constituida en vista de algún bien (...) es evidente que todas las comunidades tienden hacia algún bien, pero la que está por encima de todas las demás y a todas las incluye tenderá al bien que está por encima de todos los bienes. Y a esta comunidad, que es la comunidad política, se la llama ciudad".
} 
humana en alcanzar la autarquía, independencia y autosuficiencia, mientras que los otros tipos de koinonía son siempre en algún aspecto dependientes de otra cosa que ellas mismas.

Este orden en la explicación, que es el orden de la fundamentación de la filosofía política aristotélica, viene prescrito por las premisas onto-teleológicas del pensamiento del estagirita. Sin embargo, no coincide con el orden genético de la explicación, que es el que de hecho permite la analogía entre las koinoniai, sobre la base de una disposición a la acción cooperativa común a todas ellas, la amistad. Así, dirá Aristóteles, el mejor modo de indagar en estas cosas consiste en "observar las cosas tal como se desarrollan desde un principio" (Política, I, 2, 1252a 23) y analíticamente, dividiendo el compuesto hasta llegar a los elementos simples (1252a 18-19).

En este orden de explicación, genético-analítico, lo primero es la unión de "aquellos que no pueden existir uno sin el otro", esto es, hombre y mujer, por un lado, y amo y esclavo, por otro, unidos con vistas a la procreación y a la supervivencia (1252a 25-35). Estas uniones primarias u originarias, protai, que responden a la necesidad natural, ${ }^{14}$ dan lugar a la casa, el oíkos, "la koinonía constituida naturalmente para la vida cotidiana" (1252b 13-14). En buen orden aristotélico de fundamentación, el autor afirma: "De esas dos comunidades, entonces, la primera es la casa" (1252b 10 - mis cursivas); aún cuando, en orden analítico (que es también el de la exposición) el oíkos es segundo, ya que es una koinonía compuesta de koinoniai más simples.

Luego, constituida a fin de satisfacer necesidades "no cotidianas"15 y compuesta por una multitud de casas se encuentra la aldea, la apoikía, a la que se concibe como una extensión de cada una de las casas que la conforman, consideradas individualmente. El linaje común es aquí el vector del agrupamiento, y la estructura de la autoridad se corresponde con el mismo: es el rey quien detenta la autoridad (1252b 16-25).

Por último, "la koinonía constituida a partir de muchas aldeas, koinonía perfecta, es la polis, que alcanza ya, por así decirlo, el límite de la total autosuficiencia" (1252b 28-29). Se trata de la téleios koinonía, expresión que las traductoras comentan del siguiente modo: "Algo téleios es algo 'acabado, completo, perfecto', plenamente constituido como tal, esto es, que ha alcanzado su télos, su 'fin' o 'propósito'”. (Aristóteles, 2005: 56, nota 21). Ahora bien, a la afirmación citada en la que Aristóteles explica que la polis, esto es, la koinonía politiké, está compuesta por muchas aldeas alcanzando la autosuficiencia, inmediatamente añade: "surgió, entonces, con el fin de

\footnotetext{
${ }^{14}$ Según Riedel, “[estas] comunidades o sociedades son 'naturales' porque corresponden a la 'naturaleza' del hombre, es decir, a su naturaleza de instintos y necesidades: el instinto del ser vivo de procrear seres vivientes y la necesidad de apropiarse y gozar de las cosas; ambas necesidades tienen su sede propia en la economía de la casa". (Riedel, 1977: 130)

${ }^{15}$ Aristóteles no especifica a qué clase de necesidades se refiere aquí. Podemos presumir que se trataría de necesidades "no naturales", en el sentido de histórica- y socialmente producidas, la satisfacción de las cuales precisa una mayor "diferenciación del trabajo" que la que es posible dentro del oíkos.
} 
preservar la vida, pero existe con el fin del vivir bien" (1252b 30), y en mi opinión, la interpretación de esta frase es una clave para comprender el planteo aristotélico. Nos preguntamos: sobre la base de la explicación precedente, ¿cuál es, cuál debe ser, el sujeto de la frase para que ella sea inteligible? Se trata de una afirmación compleja, que hace referencia a un mismo sujeto de predicación colocándolo en una doble dimensión temporal y asignándosele dos fines (télos) diferentes, lo cual sería en principio una contradicción ya que la esencia, la naturaleza, el fin, de un ente se dice en singular. Entonces, de nuevo, ¿cuál es el sujeto de la oración? Me parece que por el contexto argumental se debe responder "la polis", pero no como particular de base (Strawson), sino como concepto, esto es: lo que Aristóteles tenía en mente como sujeto de la enunciación era la koinonía politiké. Luego, la frase citada se debe leer del siguiente modo: la polis, en tanto que koinonía (y al igual que las koinoniai que ella abarca y le quedan subordinadas) "surgió (...) con el fin de preservar la vida, pero existe [en tanto que koinonía politiké] con el fin del vivir bien". En efecto, sólo la polis existe en tanto que ente, es decir, tiene una existencia independiente, mientras que las otras koinoniai reciben su ser de ella, y de hecho su "existencia" a fin de preservar la vida se da en la polis, de la cual no son más que partes; así, no "existen" como fines en sí mismas, ya que sólo la koinonía politiké es fin en sí misma y ente, y el todo es anterior a las partes. ${ }^{16}$ En este sentido, Aristóteles concluye el razonamiento del siguiente modo: "Por lo tanto, toda polis es por naturaleza, si es que también lo son las primeras koinoniai. La polis es, en efecto, el fin de éstas, y la naturaleza es fin. Pues lo que cada cosa es al término de su desarrollo, eso decimos que es la naturaleza de cada cosa (...). Además, aquello para lo cual algo existe, esto es, su fin, es lo mejor; y la autosuficiencia es fin y lo mejor". (1252b 31-36 -mis cursivas) ${ }^{17}$

\footnotetext{
${ }^{16}$ La naturaleza de una cosa, en este caso de la polis, no reside en sus partes, las koinoniai, sino en el todo, esto es, al final del desarrollo de la cosa, la koinonía politiké. Pero entonces ese todo se encuentra también al inicio del desarrollo, manifestándose como la "tendencia al desarrollo", como la "fuerza" que conduce la "formación" de las partes hasta alcanzar la plenitud del todo.

${ }^{17}$ En consecuencia, me parece que se equivoca Niklas Luhmann cuando afirma que habría una paradoja en "el modo griego de pensar la sociedad", que él entiende del siguiente modo: habría una paradoja en la idea de que "un sistema social (koinonía) entre muchos otros incluye en sí, al mismo tiempo, a todos los otros", paradoja que Aristóteles resolvía "recurriendo al énfasis y, a fin de cuentas, apoyándose en una concepción ética de la política". (Luhmann y De Georgi, 1993: 44). Tal paradoja no existe si se aceptan las premisas del pensamiento aristotélico y si se entiende, al revés de lo que piensa Luhmann, que en Aristóteles hay una concepción política de la ética (EN I.1.1094 a-b), sin haber un ámbito intermedio de "lo social" o de "la sociedad". La koinonía politiké no es nunca "un sistema social entre otros". Es por el contrario, y para usar los términos de Luhmann, el "sistema social". De hecho, es el único sistema social que existe. En consecuencia, para Aristóteles la sociedad es sociedad política, $o$ no es. Ahora bien, si no me parece que haya una paradoja en el planteo aristotélico, si encuentro paradójico el hecho de que Luhmann crea que en Aristóteles hay una paradoja porque habría concebido a la sociedad de una manera muy concreta, sin recurrir a principios teóricos suficientemente abstractos, cuando en realidad es él quién no alcanza el nivel de abstracción de los principios aristotélicos y por lo tanto se ve obligado a una interpretación concretista de la koinonía politiké.
} 
Ahora bien, ¿qué clase de individuos se "asocian" para formar la polis, y con qué fin? Si el oíkos es la sociedad / comunidad del hombre con la mujer y el esclavo (y los hijos) con el fin de reproducir la vida y subsistir, bajo la autoridad / dominio del esposo - amo - padre, y si la apoikía es la sociedad / comunidad de los miembros de una multitud de casas para la satisfacción de necesidades no cotidianas, sobre la base del linaje común, y por lo tanto, bajo la autoridad / dominación regia, ¿la sociedad / comunidad de quiénes es la koinonía politiké, con vistas a qué fin, y bajo qué forma de autoridad o dominio ${ }^{18}$

Pues bien, los "miembros" de la (comunidad de la) polis en tanto "asociados políticos" son los ciudadanos, esto es, quienes tienen "el poder de tomar parte en la administración deliberativa o judicial" de una ciudad (Política, III 1 1275b 18-19). Pero este poder, esta capacidad, presupone la autonomía, la libertad, de los ciudadanos. De hecho, Aristóteles afirma también que "la polis es una koinonía de individuos libres" (Política 1279a 23). Ahora bien, esa libertad del ciudadano, del político, presupone su dominio sobre una casa y todo lo que de ella depende, sin que ello sea, sin embargo, suficiente para conferirle plena autarquía. El motivo es el siguiente: si la casa a su vez depende de otras casas para satisfacer necesidades no cotidianas, y se agrupa con otras del mismo tipo sobre la base del linaje, y esta forma de koinonía, la aldea, se corresponde con la autoridad y el dominio del rey, el "jefe" (esposo, padre, amo) de la casa no se gobierna a sí mismo, sino que depende de otro, y por lo tanto no es libre ni autónomo. Sólo cuando los hombre abandonan la tutela del rey, para gobernarse a sí mismos por medio de la ley, una ley que ellos mismos, en cuanto ciudadanos, instituyen, alcanzan la autarquía. En la aldea, la comunidad / sociedad de los seres humanos no ha alcanzado su fin, su naturaleza. Esto se logra únicamente con la determinación de los seres humanos de gobernarse a sí mismos en igualdad y libertad, de un modo justo, por medio de la ley, con vistas a la vida buena, feliz y virtuosa. Éste último es precisamente el fin propio de la koinonía politiké. Y la forma de dominio que en ella se actualiza se basa en la libertad y la igualdad de los ciudadanos, que gobiernan por turno, sobre la

\footnotetext{
${ }^{18}$ La pregunta respecto de quiénes están "asociados" en la koinonía politiké parece poner en cuestión la exposición precedente. En efecto, hasta aquí han sido las demás koinoniai las que nos han ocupado en cuanto partes de la polis, pero ahora preguntamos por la clase de los individuos que "la conforman". Pues bien, hay que tener en cuenta que Aristóteles en Política I 1 y 2 quiere determinar el ser de la polis, su concepto. Y para ello es necesario identificar la especificidad de la misma dentro de los fenómenos de su mismo género. Así una koinonía es comparada con y distinguida de otras koinoniai. En este contexto, si el individuo aislado, abstracto, no es considerado en la reconstrucción genética de la polis ello se debe a que, en primer lugar, él no es por naturaleza ni, por otro lado, prefigura la polis. Lo contrario sucede con las protai koinoniai: ellas son por naturaleza y, en cierta medida, anticipan la forma (eidos) que aparece en la polis (Riedel, 1976: 81-82) La reducción de las partes de la polis no puede conducir en Aristóteles al individuo porque éste, que no puede subsistir aisladamente, debido a su propia falta de independencia, es siempre, en última instancia -desde un punto de vista genético- miembro de una koinonía, y, en primer lugar -desde la perspectiva de fundamentación- de la polis. Ello no impide que en toda koinonía sean clases de individuos las que se "asocian" (hombre y mujer, amo y esclavo, rey y súbdito, ciudadanos), pero debe tenerse en cuenta que el resultado de la asociación es de un género distinto que el del individuo, siendo de hecho anterior a éste, ya que es la condición de posibilidad de su supervivencia y, eventualmente, de su existencia. Así, es la clase de koinonía la que determina la clase de individuos asociados, y no al revés.
} 
base de leyes estatuidas en común. ${ }^{19}$ Esto hace que la polis sea concebida, al mismo tiempo que como un particular tipo de comunidad / sociedad, como un tipo específico de organización o asociación política en el sentido moderno (que lo era, era evidente para los griegos, que precisamente por eso no necesitaban hacer la distinción comunidad-sociedad-estado), que, vía el concepto de sociedad civil, ha sido interpretado, e incluso traducido, como Estado, o ciudad-Estado.

Ahora bien, es importante ver que si el ciudadano independiente y autónomo es un presupuesto de la polis, ésta, a su vez, constituye el presupuesto de su independencia, de su ser, ya que presupone y garantiza mediante la ley el dominio del hombre sobre la casa y el gobierno de uno sobre sí mismo y sobre los demás. Así, en el ser de la polis tiene su realidad el ser del hombre. Desde de las premisas onto-teleológicas de Aristóteles, mientras la polis no existe, "el hombre" no existe, y viceversa. Sólo que el hombre no es por naturaleza, mientas la koinonía sí, es decir: el ser humano no puede existir sin koinonía, pero la koinonía sí puede existir sin un ser humano particular cualquiera. Así, la polis cambia, modifica cualitativamente al hombre. Sólo esa forma de organización social, de koinonía, le permite ser autónomo, autárquico. Luego, el hombre, en tanto único animal poseedor de logos (palabra, discurso, razón), tiene la capacidad de "expresar lo ventajoso y lo perjudicial, y por ello también lo justo y lo injusto" (1253a 16-18), lo bueno y lo malo; pero sólo la asociación en koinonía politiké permite que utilice efectivamente esa capacidad, es decir, sólo ella le concede la libertad necesaria para manifestar sus percepciones, para participar activamente en la puesta en común de las opiniones respecto de lo justo, que posteriormente se fijan en leyes. Por ello, "la virtud de la justicia (...) es algo propio de la polis, pues la justicia es la ordenada disposición de la koinonía politiké; y la virtud de la justicia consiste en discernir lo que es justo" (1253a 40-43), cosa que sólo puede lograr no el individuo aislado sino "la koinonía de quienes tienen tales percepciones" (1253a 19), constituyéndose al mismo tiempo que en la koinonía perfecta, en régimen político. ${ }^{20}$

Cabe destacar, por último, que una koinonía así constituida coincide en sus características con la forma más acabada de philía entre los seres humanos: en efecto, la koinonía politiké supone la igualdad entre los ciudadanos -todos ellos deben ser libres-, la homogeneidad en el fin -la vida buena y virtuosa- y el actuar común con vistas a ese fin. $Y$ si esa forma de amistad se identificaba con lo justo, como dijimos más arriba, entonces la koinonía politiké se identifica con lo justo, y por eso constituye la téleios comunidad / sociedad humana. ${ }^{21}$

\footnotetext{
${ }^{19}$ No puedo aquí entrar en más detalles respecto del modo en que Aristóteles concibe la vida virtuosa y justa, ni desarrollar más extensamente el concepto de régimen político (politeia)

20 "Un régimen político [politeía] es, en efecto, una organización de los poderes en las ciudades, de qué modo están distribuidos, cuál es el poder soberano del régimen y cuál es el fin propio de cada comunidad". (1289a 16-19)

${ }^{21}$ Entonces, para aclarar la exposición cabe preguntarse: ¿por qué no se trata aquí de una "teoría de la sociedad", o de una filosofía social o filosofía de la sociedad, o de una "sociología" de la polis griega, y sí, en cambio, de filosofía política? Porque en definitiva, para Aristóteles el ser humano no es meramente un ser "social". También los animales son seres sociales, si por
} 


\section{Communitas / Societas, Societas Civilis, Civitas Dei / ecclesia.}

Según Manfred Riedel, esta manera de conceptualizar la comunidad / sociedad (sobre la base de una teleología natural, que no supone diferencia de principio alguna entre comunidad y sociedad, que, al contrario, permite sostener la identidad en la diferenciación escalonada de las sociedades / comunidades, e implica la subordinación de todas ellas a -o su "realización en"- la koinonía politiké) se mantiene invariable, en lo fundamental, en la filosofía grecoromana, en el pensamiento cristiano desde San Agustín a Santo Tomás, a todo lo largo de la Edad Media, en la escolástica y en el humanismo, hasta entrado el siglo XVII (Riedel, 1977: 133-134). Y esta continuidad se da aún cuando el latín pone a disposición de los hablantes dos expresiones diferentes para un mismo concepto, lo que indudablemente sentaba las bases lingüísticas para la diferenciación conceptual. Ahora bien, según el mismo Riedel, se producen sí algunas modificaciones en los esquemas de argumentación, en sus presupuestos, y algunos agregados o ampliaciones en cuanto a lo que las expresiones, todavía sinónimas, abarcan. Cabe preguntarse entonces si estas modificaciones y ampliaciones son indicadores de cambios "significativos" en la experiencia histórica y en las premisas "teóricas" para la conceptualización de la misma, o no. La respuesta que se desprende de la presentación de Riedel parece ser que no, que no se producen cambios importantes en la experiencia y la conceptualización de la sociedad hasta el siglo XVII. Sin embargo, esa respuesta puede ser un tanto apresurada.

Parece difícil admitir que la experiencia social y política de un romano en el apogeo de la república, o de un romano en plena debacle del imperio, sea asimilable tout court a la experiencia histórica de un griego de la polis del siglo $\mathrm{V}$ a.C. Por lo demás, la particular experiencia histórica de un Cicerón viene acuñada en el cruce del pensamiento aristotélico y estoico, del mismo modo que la experiencia de Agustín supone el cruce de las Sagradas Escrituras, su interpretación paulista y el pensamiento griego neoplatónico en una situación de crisis social y política general. Se debe dar ciertamente la razón a Riedel cuando señala que no se establece en el pensamiento romano-cristiano la distinción entre comunidad y sociedad, ni tampoco una distinción entre comunidad / sociedad y estado. Ahora bien, que uno se interese por rastrear las distinciones que caracterizan al mundo moderno no debería impedir identificar e interrogar otras distinciones que caracterizan constelaciones y

ello se quiere decir que viven juntos, de un modo "organizado", a fin de reproducir y salvaguardar la vida de cada uno de ellos y perpetuar la especie. Más aún, también entre los animales hay amistad, dice Aristóteles (EN, 1155a 18-19). Pero el ser humano no sólo es un ser social en este sentido. Aristóteles afirma que el ser humano es un politikón zóion, un animal político, y eso porque tiene logos (palabra/discurso/razón). El logos es lo que le permite distanciarse de la reproducción mecánica de la vida biológica y pensar lo bueno y lo justo, y actuar de acuerdo con esa intelección. Así, es el lenguaje lo que diferencia a los animales de los seres humanos, $y$ no porque haga a los seres humanos seres sociales, cosa que los animales también son, sino porque los hace seres políticos, seres no sólo dispuestos a la vida en común sino más bien dispuestos a la vida justa en común. Por eso la forma de asociación propiamente humana es la asociación política, koinonía politiké, polis, y no la mera asociación (koinonía = comunidad /sociedad) natural en vistas a la reproducción y la supervivencia. 
rupturas históricas pasadas pero que son o pueden ser relevantes, al menos indirectamente, como indicadores de líneas de fuga, o como posibilidades eventualmente actualizables.

En lo que sigue, abordaré breve y esquemáticamente el pensamiento en torno a la comunidad / sociedad en Cicerón y en San Agustín. La idea / hipótesis, que guiará las exposiciones es la siguiente: me parece que en el contexto de "una sociedad" adquiriendo las dimensiones del imperio romano, y luego en el contexto de su desintegración, la que para nosotros es la brecha entre comunidad y sociedad debió abrirse, percibirse y quedar reflejada de algún modo. Intentaré mostrar de qué modo, si no a través de la contraposición entre communitas y societas.

Como ya dijimos, Cicerón recepciona en latín el pensamiento aristotélico y traduce koinonía indistintamente por communitas y / o societas, diferenciando al igual que el estagirita sólo los distintos "grados" o "niveles" en que se forman sociedades / comunidades. Un rasgo distingue sin embargo la concepción ciceroniana respecto de la de Aristóteles: es la ampliación de la comunidad / sociedad, sobre bases "naturales", para abarcar a la humanidad, con lo que el concepto genérico deja de ser el de comunidad / sociedad política (o civil) para ser el de societas humanas. Consecuentemente, se pasa del politikón zóion al animale sociale. Ahora bien, contra el fondo que constituyen el concepto genérico ampliado, por un lado, y la graduación escalonada de las societates, por otro, se destaca o adquiere prominencia, en el pensamiento ciceroniano, la comunidad / sociedad denominada civitas (= societas civilis = koinonía politiké) o república. Esto no sucedía en la conceptuación aristotélica ya que la civitas sive societas civilis no tenía un concepto "superior" o más amplio sobre el cual destacarse. Enseguida citaré los textos correspondientes. Antes, una aclaración.

Cabe señalar que la ampliación del concepto de comunidad / sociedad para abarcar con él al género humano no supone el rechazo del derecho como factor constitutivo de la comunidad / sociedad (y con él, la organización "civil" y "política" de la sociedad / comunidad). En efecto, esa ampliación del concepto de comunidad / sociedad tiene como su condición de posibilidad la creación de la figura del "derecho extranjero" dentro del derecho romano. Se quebraba así la delimitación jurídica de la polis hacia fuera, que se enfrentaba con lo extranjero como con lo radicalmente otro, lo bárbaro, lo fuera de la ley. El peregrini, el gentium, queda ahora "integrado" en la comunidad / sociedad. Esta ampliación del derecho, a su vez, es justificada a través de los "principios naturales de la sociedad humana". Entre ellos,

"el primer principio es el que pertenece a todo el género humano, es la razón y el habla, las cuales, enseñando, aprendiendo, comunicando, discutiendo, juzgando, hermanan entre sí a los hombres y los unen en una sociedad natural. (...). Y esta sociedad de los hombres entre sí, de todos juntamente con todos, tiene una extensión amplísima. En ella deben ser comunes todos los bienes que produjo la naturaleza para uso común de los hombres" (Cicerón, 1997: 28). 
Así, a diferencia de los griegos, los romanos consideran que incluso aquellos que no hablan la propia lengua, en tanto que sean capaces de hablar, y en tanto que les pueda ser enseñada la lengua ajena, forman parte de la "sociedad natural" que representa la societas humanas. Luego, y más allá de las "cosas" para el uso común de la humanidad, se encuentran aquellas que "están atribuidas a los particulares por las leyes o por el derecho civil" (Ibíd.) Ahora bien, "lo privado", "lo particular", no aparece aquí sólo como "lo del individuo", sino también como aquello que, por ley, es restringido a grupos más pequeños que la humanidad, hasta alcanzar, eventualmente, al individuo. Si el lenguaje y la razón son "cosas" de "propiedad común", el derecho al agua, y a encender un fuego, pero también a la participación política, a la ayuda mutua, a la residencia, el deber de combatir para defender la república, de pagar impuestos, etc., son "cosas" que se reservan diferencialmente a determinados grupos, de las cuales están "privados" otros grupos, y son determinadas como tales por la ley.

\section{Sobre la base de estas ideas Cicerón afirma:}

"hay muchos grados en la sociedad humana. Bajando de aquella infinita y universal, la más inmediata es la de una misma gente, una misma nación, una misma lengua, por la cual sobre todo se sienten unidos los hombres. Todavía es más íntima la de una misma ciudad (civitates), porque hay muchas cosas que las ciudades usan en común: el foro, los templos, los pórticos, las calles, las leyes, el derecho, los tribunales, los sufragios, las relaciones familiares, las amistades, muchos negocios y contratos particulares. Más estrecho todavía es el vínculo que forman los miembros de una misma familia: ella reduce a un círculo limitado y pequeño la sociedad inmensa del género humano". (Ibíd.: 2930)

A continuación, Cicerón emprende el camino inverso, reconstruyendo los niveles de constitución de comunidades / sociedades humanas pasando por el matrimonio, la civitas o republica, hasta la societas humanas. Baste el texto citado para mostrar cómo la relaciones contractuales, comerciales, incluso el mero el intercambio de favores (lbíd.: 31), caen bajo un mismo concepto que las relaciones familiares y las amistades, al igual que la societas civilis, que a través de los representantes, los cónsules y los senadores, fija la ley y el derecho para la determinación de la ciudadanía y la extranjería, de lo común y lo privado, es decir, para la constitución de la propia societas civilis, de la comunidad política que se ocupa precisamente de "la cosa publica", la respublica, y para la delimitación de los otros como extranjeros, de los no ciudadanos, excluidos de la sociedad civil pero aún así miembros de la sociedad del género humano.

Entonces, en orden "descendente", y sin pretender exhaustividad, quedan las comunidades / sociedades así escalonadas: sociedad humana, "nación", civitas (societas civilis, respublica), ciudad (en sentido moderno, para lo que en latín se usaba la palabra urbs), colonia, casa y familia (lbíd.: 30). Y sin embargo, el propio Cicerón se apresura a aclarar: "Pero cuando se examina diligentemente 
y se considera todo, se advierte que no hay sociedad más venerada ni más digna de nuestro amor que la que cada uno de nosotros tiene con la República", ya que ella "comprende a todos y cada uno de los que nos son queridos" (Ibíd.: 31).

En efecto, la comunidad / sociedad de la república es la del pueblo (populus), y "a people is not any group of men assembled in any way, but an assemblage of some size associated with one another through agreement on law and community of interest and customs" (Cicero, 1999: 18). De hecho, la civitas o societas civilis es aquel estado en el cual, por un lado, todos se encuentran unidos unos con otros por vínculos legales, de derecho (vinculum iuris), al mismo tiempo que, por otro lado, comparten un modo de vida, costumbres, inclinaciones y, con ellas, voluntades. (Cicerón, 1997: 30-31. Ver también Fisteti, 2004: 58 y ss.) Aquí, entonces, como ya antes en Aristóteles, no sólo no se reconoce diferencia alguna entre comunidad y sociedad sino que tampoco se reconoce ninguna diferencia entre sociedad y estado. Pero, y esto es lo que me interesa destacar, la preeminencia concedida a la república o al pueblo, sobre la base de los rasgos indicados, establece sí una distinción con comunidades / sociedades más amplias e indeterminadas, como las "naciones", las "gentes" y, en última instancia, la sociedad humana. Aquí aparece por primera vez una distinción que, si bien no supone oposición ni asimetría, como la posterior distinción moderna comunidad / sociedad, si queda alineada con ella a partir del eje lo cercano / lo lejano con respecto de la propia experiencia vital.

Es cierto, como apunta Koselleck, que en el pensamiento de la Stoa "no se trata de conceptos que se excluyan mutuamente, sino de conceptos complementarios de diferente orden de magnitud" lo cual permite evitar que la dualidad se nutra de la negación (Koselleck, 1993: 220). Pero no es menos cierto que los conceptos son distinguidos y que, al menos en lo que refiere a Cicerón, es la república, la sociedad del populus, la sociedad más "venerada" y "digna de nuestro amor", y no la sociedad humana en general. Entonces, en lugar de comunidad vs. sociedad, encontramos aquí la distinción societas civilis \# societas humanas. Si bien los dos polos de la relación tienen aquí "valor positivo", por primera vez se encuentra que a partir de la distinción (lo que diferencia el planteo de Cicerón del de Aristóteles, en el cual no hay distinción posible) es el polo "más cercano" a la experiencia vital del individuo que el adquiere preeminencia. Y es ésta relación, entre dos tipos de comunidad / sociedad, ambas positivamente valoradas, entre la cuales la más "cercana" al individuo tiene la preeminencia, la que se invierte radicalmente con la debacle del imperio romano reflejada en la imposición del pensamiento cristiano sobre el pensamiento estoico, más específicamente, reflejada en el pensamiento agustiniano. Inversión que se produce en San Agustín no recurriendo a la distinción comunidad / sociedad (terrenas) sino a la distinción ciudad terrena / ciudad de Dios.

El pensamiento político-social de San Agustín es sumamente complejo. Me aproximaré a él de un modo muy esquemático y tentativo. De hecho, antes que el conjunto de su perspectiva sobre la sociedad, lo que me interesa investigar 
son los recursos conceptuales de este autor, y el manejo que hace de los mismos. ${ }^{22}$ Así, siguiendo a Todd Breyfogle, intentaré reconstruir las premisas y la terminología relevante sólo hasta el punto en que se haga visible lo que se puede considerar una salida conceptual viable (y de hecho, una que ha resultado muy influyente en la historia social y política posterior), típicamente cristiana, a la dificultad histórica y conceptual de identificar, designar y delimitar el propio grupo de pertenencia en un contexto de acelerada transformación (desintegración) de las estructuras sociales vigentes (más específicamente, del imperio romano en general) sobre la base de una conceptuación heredada que no pone disposición más que un esquema escalonado de societates que va, sin solución de continuidad, del matrimonio a la humanidad. ${ }^{23}$

El punto de partida en lo que podríamos, quizás, llamar la "teoría de la sociedad" de San Agustín es el amor. ${ }^{24}$ El amor sería aquello que mueve a las personas, es la esencia de voluntad. Abarca actitudes, deseos y aversiones hacia las cosas, hacia ciertas ideas u opiniones, hacia los demás, hacia uno mismo y hacia Dios. Las formas del amor y los "objetos" susceptibles de ser amados son múltiples. El amor, en sus distintas formas, y orientado hacia diversas cosas, se manifiesta asimismo bajo diversas formas, por ejemplo como motivos transitorios, profundos rasgos de carácter y orientaciones fundamentales en la vida. En cualquier caso, dos clases de amor son las más importantes. Por un lado, el amor hacia algo por sí mismo, por su absoluto valor intrínseco. Por otro lado, el amor hacia algo por la utilidad o el placer que depara a las personas. Sólo aquello que es digno de ser amado por sí mismo es capaz de conferir verdadera felicidad, trayendo el apaciguamiento de los deseos, el cese del miedo. Sólo Dios es digno de ser amado de este modo. Sólo el amor a Dios es verdadero amor. Ninguna otra cosa, ningún objeto, criatura o hecho es digno de ser amado completamente por sí mismo. El amor por las cosas temporales, por cualquier cosa excepto Dios, es una perversión del amor. Luego, la justicia perfecta consistiría en amar a cada cosa, incluyendo a Dios, de acuerdo con su valor, y en amar las cosas del mundo por amor a Dios.

Estas formas del amor son terrenales. Es como seres mundanos que amamos, y como seres que vivimos entre las cosas y con otros, que necesitamos de otros y del mundo, debemos amarlo/as. Sin embargo, lo que la caída, el pecado, ha producido es un desarreglo de nuestro amor, por el cual nos damos a nosotros mismos, a nuestros deseos y a los objetos de nuestros deseos indebida importancia, somos incapaces de percibir que los méritos de las cosas no se corresponden con el modo en que las amamos y buscamos la felicidad

\footnotetext{
${ }^{22}$ Para lo que sigue, me apoyo en: Weithman, 2006; en: Fortin, 1987; pero fundamentalmente en Breyfogle, 2009, trabajo sumamente exhaustivo para lo que a mi me interesa aquí.

${ }^{23}$ Téngase en cuenta que Agustín no puede conformarse con la estrategia de Cicerón, que consistía en conceder preeminencia a la república, porque son precisamente la civitas romana y el populus los que pierden, en época de Agustín, su capacidad de identificación y contención, los que dejan de representar referencias estables, esquemas de interpretación y orientación válidos.

${ }^{24}$ Para lo que sigue, sobre el amor, Weithman, 2006: 235-236.
} 
en cosas que no nos la pueden dar. Especialmente, la buscamos en la satisfacción de las inclinaciones y en el poder y la dominación sobre otros. Sin embargo, el desorden de nuestro amor no llega a ser tal que nos impida absolutamente entrever el orden correcto, visión que produce en todos los seres humanos conflictos internos y conflictos con los otros, luchas internas y externas. Por este motivo, todas las vidas humanas y todas las relaciones interhumanas son, en este mundo, conflictivas.

El conflicto, en última instancia el pecado, no impide, sin embargo, la sociedad. De hecho, para San Agustín los seres humanos son sociales por naturaleza, han sido creados para vivir en sociedad, necesitándose unos a otros, y todas las relaciones entre ellos constituyen sociedades, societates. El concepto de sociedad, societas, refiere en San Agustín a todas las formas de asociación o relación entre seres o "personas", humanas o divinas. Así, el concepto de sociedad abarca "trading partnerships, friendship, marriage, household and neighborly relations (including community of interests), political associations, the community of mankind, both demonic and angelic community, and the community of divine persons" (Breyfogle, 2009: 504). Todos estos agrupamientos, todas estas relaciones, son sociedades. Entre los seres humanos (ya sea terrenalmente, bajo la condición de la caída, o en el paraíso, con anterioridad al pecado original) todas las relaciones, cualquiera sea el grado de intimidad o anonimidad, armonía o conflicto, dan lugar a societates, porque los seres humanos no son autosuficientes y porque comparten los dones del intellectus y la voluntas (y en este plano, San Agustín coincide con Aristóteles y Cicerón).

Ahora bien, con anterioridad a la caía, no existían reservas, desacuerdos o conflictos entre las personas. En el paraíso los seres humanos vivían en una sociedad pacífica, perfecta, en una socialialidad completa, compartiendo los frutos del intellectus y las orientaciones de la voluntas. Se trata de una sociedad "where all share 'the full enjoyment of the beauty of reason' and there will no longer conflict because they rest in that trae peace, 'the will willing nothing unbecoming and yet retaining its freedom' (De civ. D. 22.30) (...) the peace of the heavenly city is 'the most ordered and harmonious society in the enjoyment of God and of one another in God' (De civ. D. 19.13)" (Breyfolge, 2009: 504). Así queda caracterizada también la civitas Dei. Se trata de la sociedad perfecta, la sociedad de los justos en su amor a Dios, bajo el mando de Dios y en total obediencia a él. Cabe observar aquí que es la institución de la ley para el dominio y la obediencia lo que distingue al tipo de societas que es una civitas de las demás societates. En este caso, se trata de la ley divina, y por ello de la civitas Dei, en el contexto de la cual se encuentran todas las demás formas de sociedades perfectas.

Pero el pecado es intrínsecamente una ruptura de esta sociabilidad perfecta, de esta civitas celestial escatológica. Desde entonces, hemos sido expulsados del paraíso, para vivir terrenalmente, y la perversión del correcto modo de amar, la total confusión en cuanto al valor de las cosas por las cuales y hacia las cuales orientamos nuestras vidas, introduce la separación y el conflicto entre las personas, la discordia intelectual y el choque de las voluntades. La 
codicia y la avaricia son las raíces del mal, tanto en el cielo como en la tierra. En el cielo, es decir, escatológicamente, el mal introduce la ruptura entre la civitas Dei y la civitas terrena. En la tierra, fomenta, hasta el día del juicio fin, el conflicto y la guerra. Así, con el pecado, la caída desde el paraíso y la confusión por la cual el bien privado, el bien propio, sustituye al bien común, se perfilan al mismo tiempo las dos ciudades escatológicas, todas las sociedades bajo la condición del pecado, incluyendo las civitas in ordo temporum históricamente existentes (Asiria, Roma, etc.), y la ecclesia.

Entonces, reteniendo el modelo aristotélico para la conceptuación de la comunidad / sociedad como un proceso unitario escalonado de "societates", por un lado, y la ampliación propia del pensamiento político romano por la que el concepto más amplio es el de la societatis humanae, por el otro, cuando San Agustín reflexiona en torno a las sociedades terrenales entre todas las societates posibles son dos las que más le interesan: la ecclesia y las distintas civitas históricamente existentes. Estas son los reflejos temporales, ambos deformados e imperfectos de las civitates escatológicas: la civitas Dei y la civitas terrena, correspondientemente. Ahora bien, puesto que en la tierra la serie entera de las sociedades que puedan constituirse está marcada por el pecado siendo por ello imperfectas, también la ecclesia, reflejo terrenal de la civitas Dei, lo es. Pero además la ecclesia no es una ciudad, una civitas. La ecclesia es la sociedad histórica de los ciudadanos (escatológicos) de la civitas Dei, quienes aún siendo ciudadanos de concretas civitates históricas, viven en la tierra como peregrinos amando por sobre todas las cosas a Dios. Las ciudades (civitas), bajo la condición del pecado y en la tierra, son las sociedades constituidas a través de la institución humana de la ley coercitiva para la dominación y la obediencia de unos seres humanos por otros. Así, en el mundo, se es siempre miembro de una sociedad política, de una ciudad determinada, al mismo tiempo que se pertenece a muchas otras sociedades (familia, amigos, organizaciones de diverso tipo, humanidad) pero no necesariamente se es un peregrino, esto es, un miembro de la ecclesia, un cristiano. De ahí la oposición entre los cristianos y los paganos.

Tenemos así, con el concepto del amor y con la definición de los principales tipos de asociación que interesan a San Agustín, los recursos para comprender de qué modo -a partir de las premisas y principios para la interpretación de la historia de la creación y del mundo fijadas en las Sagradas Escrituras- en el contexto de la debacle del imperio romano son conceptualizadas las relaciones de los individuos entre sí, sus grupos de pertenencia y sus relaciones de inclusión o exclusión, conflicto o harmonía con otros grupos. En todo caso, se trata de dar con los recursos conceptuales con los cuales el pensamiento cristiano podía designar los ámbitos primarios de socialización y pertenencia de los individuos, los grupos en los cuales se encontraba cobijo, pero también realización. Y es interesante advertir cómo a partir del principio de la fe, norma indiscutida para la conducción de la vida y la intelección de la verdad, la pertenencia primaria del sujeto no puede más que alejarse de su vivencia social y política inmediata. 
San Agustín afirma que debe rechazarse la definición de pueblo (populus) de Cicerón fundada en la ley y la costumbre para reemplazarla por una que tenga en el amor su elemento fundante. En ese caso, se puede decir "that a people is an assemblage of reasonable beings bound together by a common agreement as to the objects of their love", y entonces, "in order to discover the character of any people, we have only to observe what they love... and it will be a superior people in proportion as it is bound together by higher interests, inferior in proportion as it is bound together by lower (De civ. D. 19.24)" (Breyfogle, 2009: 507). Sobre la base de este criterio, dos son las sociedades / comunidades a las cuales el individuo debe aspirar. Por un lado, y en primer lugar, la civitas Dei, la sociedad perfecta, en la que se ama a cada cosa, a los demás, a uno mismo y a Dios por su valor. Por otro lado, bajo la condición del pecado, la ecclesia, la sociedad / comunidad de quienes rechazan los bienes mundanos y conducen su vida en el amor a Dios, amando las cosas de este mundo según el criterio divino. Esta sociedad no es una civitas. No tiene límites territoriales definidos. Sus miembros no conviven, no comparten necesariamente costumbres, hábitos, leyes. $Y$ sin embargo, es ésta la sociedad más perfecta que se puede obtener en la tierra. Es la sociedad / comunidad de los cristianos. Luego, las civitas históricamente existentes, cualquiera sea, son males necesarios. En ellas dominan el egoísmo y la avaricia, el deseo de poder y la coerción. No se puede amar este tipo de sociedades, no se puede abrazar la membresía a las mismas con el corazón, sino sólo instrumentalmente. Se trata de asociaciones coercitivas para el mantenimiento de la paz, fundadas en el desarreglo del amor. Del mismo modo, las demás sociedades, familia-aldeanación, son también necesarias, pero sólo para la satisfacción de las más diversas necesidades vitales.

Como se ve, no se combaten aquí el desarraigo y la desorientación producidos por la crisis social y política del imperio mediante un nuevo arraigo en la sociedad / comunidad local y sus valores y costumbre mundanos sino, al revés, mediante el arraigo en la sociedad / comunidad trascendente, fundada en el valor absoluto y eterno del amor a Dios. Ni siquiera se apela a la propia civitas en este mundo, como podría haber hecho un Cicerón en las mismas circunstancias, sino a la civitas del más allá. El individuo está llamado a alejarse del mundo y de los demás. Se trata de recalar en la fe. Y se podría decir que la fe, para el sujeto que la tiene, es lo más inmediato, la experiencia más básica. Pero en todo caso se trata de un repliegue de la subjetividad sobre sí misma, y por lo tanto, de un rechazo de sus vínculos inmediatos con los demás. Ciertamente no para vivir en la más absoluta soledad, sino al contrario, en la más perfecta sociabilidad. Pero se trata de una sociabilidad / comunidad que no es de este mundo.

\section{Conclusión}

Partiendo de la exposición detallada del pensamiento aristotélico sobre la koinonía he intentado mostrar en la segunda parte de este trabajo que en el pensamiento post-aristotélico, sea el de Cicerón, sea el de San Agustín, una tensión, incluso un conflicto, habita el único concepto (que no palabra) de que 
los pensadores disponían para referirse a todo aquello que, para nosotros, sólo puede ser representado a través de la articulación de dos conceptos diferentes. ${ }^{25}$ La experiencia histórica particular (moderna) que estos conceptos contrarios y asimétricamente relacionados constituyen y expresan, tuvo que encontrar entonces, si es que un problema 0 , tal vez, desgarramiento social similar tuvo lugar, otros causes conceptuales para ser elevado a conciencia y tematizado. No se trata ni puede tratarse, en cualquier caso, de una misma experiencia (aunque más no sea porque no pudo ser pensada, y con ello vivida, del mismo modo), pero tal vez sí de una experiencia "similar", desde el momento en que lo que parecería estar en juego es la experiencia de la inserción individual en grupos que o bien son susceptibles de ser aprehendidos, conocidos, vividos e integrados en y desde el propio contexto vital o bien no lo son, perteneciendo a dimensiones del mundo social alejadas de la experiencia cotidiana subjetiva. No se trata, claro está, solamente de la experiencia vital, sino también de las premisas que en cada caso sirve para la valoración de la misma. Pero en la constelación que forman experiencias y premisas teóricas, y en la variación de unas y otras, nada lleva necesariamente a los conceptos de comunidad y / o sociedad para la aprehensión y constitución de las identidades y pertenencias sociales. Comunidad y sociedad son opciones modernas. Koinonía politiké, civitas, populus, ecclesia, son otras tantas maneras de nombrar "lo mismo", sobre trasfondos diferentes, y diferentemente valorados: los bárbaros, la societates humanae, la civitas terrena, el oíkos, la familia, la aldea, los amigos, etc. Estos nos parecen conceptos a los que en un sentido laxo podríamos quizás llamar "equivalentes funcionales" del par moderno comunidad / sociedad.

Este extenso trabajo ha consistido fundamentalmente en un ejercicio de reflexión inspirado en la disciplina de la Historia Conceptual. Sin embargo, creemos que este tipo de planteos pueden enseñarnos algo sobre nuestros esquemas conceptuales, y en ello está la ganancia. Esto puede verse, por

\footnotetext{
${ }^{25}$ A modo de hipótesis se podría señalar que esta tensión surge como consecuencia no buscada de la ruptura con la delimitación jurídica de la polis por medio de la cual lo propio (la propia identidad, la propia comunidad, la propia sociedad) se confunde con lo ajeno, lo extraño (la otra comunidad / sociedad) llevando a la ampliación del concepto genérico de comunidad / sociedad hasta abarcar a la humanidad. Los bárbaros ya no son animales, y así helenos, bárbaros y romanos quedan entrelazados, siendo las identidades (las propiedades) de cada uno de los grupos sumamente porosas, más o menos indeterminadas. Es un problema de atribución: se constata que muchos rasgos considerados exclusivos de uno u otro grupo, en realidad son compartidos. Ahora bien, la humanidad, a diferencia de la polis, no es ni puede ser un colectivo del cual se pueda tener una impresión vívida, una experiencia directa, esto es, un colectivo del cual se pueda ser miembro y participante activo, a menos que se haga un enorme esfuerzo de abstracción y generalización. De allí que aún cuando el polo de lo otro (ahora la humanidad) no tenga valor negativo (como lo tenían los bárbaros respecto de los helenos), sea sin embargo necesario identificar el polo de lo propio con más fuerza, dándole la preeminencia que la propia experiencia e inserción vital tiene frente a las abstracciones del pensamiento. Esta hipótesis, a la luz de nuestro trabajo, presenta por lo menos un problema: "funciona" con respecto a Cicerón, y no para San Agustín. Sin embargo, se podría salvar el problema insistiendo en la inversión de los términos que supone el cristianismo agustiniano y en la coerción conceptual que ejercen las premisas teológicas-escatológicas.
} 
ejemplo, analizando algunas ideas de Talcott Parsons, a la que todavía hoy se puede considerar fructíferas (Fisteti, 2004, y Sciortino, 2005).

En una de las primeras definiciones de la comunidad societal por parte de Parsons aparecen, como ejemplos históricos del tipo de comunidad / sociedad al que la expresión hace referencia, varios de los conceptos que hemos desarrollado: así, dice Parsons: "Llamaremos comunidad societal al núcleo estructural de una sociedad; de forma más específica, a los diferentes niveles de evolución, se le llama tribu, o 'el pueblo' [Cicerón] o polis [Aristóteles] en la Grecia clásica o nación ${ }^{26}$ en el mundo moderno. Es la estructura colectiva en la que sus miembros están unidos o en cierto modo asociados; su propiedad más importante es el tipo y el nivel de solidaridad que -en el sentido durkheimiano del término- caracteriza las relaciones entre sus miembros" (Parsons, 1977: 712).

Como se ve, Parsons recoge, en la segunda mitad del siglo $X X$, en una expresión compuesta, cuya inestabilidad radica precisamente en la artificialidad de la composición, aquello que, desde Aristóteles, y hasta Tönnies, no había encontrado distinción. Ahora bien, que las diferencias entre los distintos esquemas conceptuales son tan importantes como las similitudes (teóricamente fundadas o aparentes) es algo que se debe recordar siempre, y que Parsons parece olvidar, sobre todo si se quiere ser consecuente con las enseñanzas de la historia de los conceptos. Las categorías historiográficas y los conceptos del pasado, cuando son apropiadamente reconstruidos, abren para el historiador la realidad vivida por otros, pero los conceptos también constituyen, hacen experimentable y estructuran la historia para quien la vive, es decir, para cualquier ser humano. Por ello, la existencia misma de los colectivos (grupos, estructuras sociales y políticas o hechos sociales) a los que hemos hecho referencia depende de su conceptualización, y en ese sentido son-fueron- desde el punto de vista de los individuos históricos concretos que los experimentan tal y como los conceptos de que disponen los hacen accesibles. Si las ciencias sociales no quieren eliminar de hecho, esto es, prácticamente, la historia, se habrán de observar con cuidado las diferentes conceptualizaciones. ${ }^{27}$ Teniendo a la vista el modo en que Parsons introduce el concepto de comunidad societal en el fragmento citado, así como el proceder de la trituradora conceptual luhmaniana (ver nota al pie \# 17), se puede parafrasear a Marx: si es verdad que las categorías de la teoría de sistemas poseen cierto grado de validez para todas las otras formas de sociedad, esto debe ser tomado cum grano salis... La diferencia será siempre esencial. ${ }^{28}$ También se puede recordar a Schlegel: "No se puede decir que algo es, sin decir lo que es. Al pensarlos, se refieren los facta a conceptos y no es indiferente a cuáles".

\footnotetext{
${ }^{26}$ Sobre la idea de "nación" como factor de integración moderno, el texto de Habermas, publicado como anexo a su libro de 1992, Facticidad y validez, "Ciudadanía e identidad nacional".

${ }^{27}$ Desde esta perspectiva, el planteo de Espósito (ver nota al pie \# 7) es un buen ejemplo de que también la filosofía más "crítica" puede ser críticamente reduccionista.

${ }^{28}$ Ver: Marx, 2005: 27.
} 


\section{Bibliografía}

(2007) Aristóteles. Ética Nicomaquea, Colihue, Buenos Aires. (Trad. de Eduardo Sinnott.)

(2005) Aristóteles. Política, EUDEBA, Buenos Aires. (Trad. de M. I. Santa Cruz y M. I. Crespo.)

(1994) Brandom, R. Making it explicit, Harvard University Press, Cambridge.

(2009) Breyfogle, T. "Citizenship and Signs: Rethinking Augustine on the Two Cities" en: Balot R. K, (ed.) A companion to Greek and Roman Political Thought, Blackwell.

(1997) Cicerón, M. T. Sobre los deberes, Altaya, Barcelona.

(1999) Cicero, M. T. On the Commonwealth and On the Laws, Cambridge University Press, Cambridge.

(2003) Espósito, R. Communitas, Amorrotu, Buenos Aires.

(2004) Fisteti, F. Comunidad, Nueva Visión, Buenos Aires.

(1987) Fortin, E. "St. Augustine", en: Strauss and Cropsey (ed.), History of political philosophy, The University of Chicago Press, Chicago, 176-205.

(2005a) Gadamer, H.-G. Verdad y método, Sígueme, Salamanca.

(2005b) Gadamer, H.-G. Verdad y método II, Sígueme, Salamanca.

(2003) Grondin, J. Introducción a Gadamer, Herder, Barcelona.

(2004) Habermas, J. Historia y crítica de la opinión pública, Gili, Barcelona.

(1993) Koselleck, R. Futuro pasado. Para una semántica de los tiempos históricos, Paidós, Barcelona.

(1996) Koselleck, R. "A Response to comments on the Geschichtliche Grundbegriffe" en: Lehmann y Richter (ed.), The meaning of historial terms and concepts, German Historial Institute, Washington.

(2009) Koselleck, R. "Introducción al Diccionario histórico de conceptos políticosociales básicos en lengua alemana", en: Revista Anthropos, N 223, Barcelona. (1993) Luhmann, N. y De Georgi, R. Teoría de la sociedad, Universidad Iberoamericana, México.

(2005) Marx, K. Elementos fundamentales para la crítica de la economía política 1, Siglo XXI, México.

(1997) Parsons, T. "Sistemas Sociales" en: Sills, D. (ed.) Enciclopedia Internacional de Ciencias Sociales, Aguilar, Madrid.

(1976) Riedel, M. Metafísica y metapolítica, Alfa, Buenos Aires.

(1977) Riedel, M. Metafísica y metapolítica II, Alfa, Buenos Aires.

(2005) Sciortino, G. "How Different Can We Be? Parsons's Societal Community, Pluralism, and the Multiculturalism Debate", en: Fox, Lidz y Bershady (eds.), After Parsons. A Theory of Social Action for the Twenty-First Century, Sage, New York.

(1947) Tönnies, F. Comunidad y Sociedad, Losada, Buenos Aires.

(2004) Weber, M. Economía y Sociedad, FCE, México.

(2006) Weithman, P. "Augustine's political philosophy" en: Stump, E. (ed.) The Cambridge Companion to Augustine, Cambridge University Press.

(2008) Williams, R. Palabras clave. Un vocabulario de la cultura y la sociedad, Nueva Visión, Buenos Aires. 